\title{
A ESFERA DOS DIREITOS: AS ORIGENS DO POLÍTICO E O PROCESSO DE AFIRMAÇÃO DO CONSTITUCIONALISMO NA AMÉRICA
}

\author{
Roberto Bueno \\ Universidade Federal de Uberlândia
}

\begin{abstract}
The crisis of Western contemporary democracies conect with the losing of efficacy of human rights and freedom which that system pretended to assert. This article looks to introduce and analyze the political and constitutional concepts which guided the founding period of the USA and to plan its relevance in the contemporary debate on democracy. To carry out this aim we suggest the analysis of some topics of the constitutional and political works of Jefferson and Madison on the concepts which inspired the debate and the building of political and judicial culture in the preconstitucional period of North America. Using this approach we will analyse some of the aftermath at the democratic culture of the occidental world which can be found in the source of the moments of crises.
\end{abstract}

KEYWORDS: constitucionalism, republicanism, democracy, founding fathers, conservatism.

RESUMO: A crise das democracias ocidentais contemporâneas conecta com o déficit de eficácia dos direitos humanos e liberdades que ela pretendeu assegurar. Este artigo procurará retomar alguns dos conceitos políticos e constitucionais que orientaram o período fundacional norte-americano e projetar sua relevância no debate contemporâneo sobre a democracia. Para cumprir este objetivo propomos a análise de alguns tópicos dos trabalhos político-constitucionais de Jefferson e de Madison acerca dos conceitos que inspiraram o debate e criação do caldo cultural político e jurídico da vida pré-constitucional norteamericana. A partir desta abordagem pretendemos analisar algumas das conseqüências junto a cultura democrática do mundo ocidental e que podem ser encontrados à raiz de seus momentos de crise.

PALAVRAS-CHAVE: constitucionalismo, republicanismo, democracia, founding fathers, Conservadorismo. 


\section{INTRODUÇÃO}

A crise das democracias ocidentais contemporâneas conecta-se com o déficit de eficácia dos direitos humanos e liberdades que ela pretendeu, e todavia pretende, assegurar. Neste sentido, este trabalho procurará imergir e analisar os conceitos políticos que orientaram o período fundacional norteamericano com a finalidade de que possa servir em alguma medida como referencial mais preciso às atualizações que as novas dimensões históricas reclamam.

Para cumprir este objetivo propomos a análise do processo político do período bem como de suas circunstâncias históricas como pano de fundo para melhor compreender a forma e os meios como ambas se projetaram e influenciaram o direito e, em especial, o constitucionalismo e os direitos humanos.

Neste artigo pretendemos abordar as raízes do constitucionalismo e os desdobramentos da construção de conceitos políticos caros à cultura democrática do mundo ocidental precisamente em um momento de crise de seus preceitos básicos, mesmo ali onde ela experimentou este seu desenvolvimento básico. Procuraremos focar algumas das principais referências bibliográficas de Jefferson e Madison no sentido de retomar certos conceitos fundamentais que inspiraram o debate e criação da América em seu momento pré-constitucional e o período mesmo da elaboração e posta em vigor de sua primeira Constituição. Para alcançar o objetivo, dividiremos o trabalho em duas partes. Em uma delas o foco residirá sobre o político, strictu sensu, com maior atenção sobre o período fundacional norteamericano. Em uma segunda parte do trabalho dedicaremos atenção à repercussão do trabalho político dos fundadores sobre o desenvolvimento da teoria jurídica norte-americana, principalmente no que concerne ao debate sobre o poder, à teoria da interpretação e ao asseguramento dos direitos fundamentais.

Neste contexto cabe dizer que o processo de desenvolvimento constitucional norte-americano tem como um importante componente do eixo argumentativo-conceitual de republicanismo. Este é o elemento que aparece de forma influente ao lado de outros que emergirão neste artigo de sorte a compor o núcleo argumentativo em torno da ideia-reitora deste artigo, vale dizer, o debate sobre o constitucionalismo e suas ramificações com a filosofia política e jurídica através dos Founding Fathers e, em especial, do debate Jefferson-Madison. 
O processo constitucional na América não teve outra origem senão o da afirmação de princípios de ordem filosófico-política em torno à liberdade, aspiração em parte originada na imigração britânica. Este foi processo de notado verniz religioso cujas origens remontavam à própria colonização da América. A liberdade religiosa viria a ocupar lugar privilegiado no conjunto das liberdades constitucionais em fase de positivação. Por este motivo esta liberdade acabou considerada por muitos, e não sem razão, como a mãe das liberdades constitucionais norte-americanas. Pode subsistir um equívoco em interpretar que Jefferson, bem como toda a posterior cultura jurídica norteamericana, se mostrou inclinada pela defesa da liberdade religiosa.

Jefferson ressalta a prioridade do papel exercido pela liberdade de crença bem como pelo livre debate, direito de livre expressão de opiniões e de imprensa. Estes seriam elementos cuja poderosa dinamização nos valores da vida política republicana seriam disseminados através do constitucionalismo. Os citados são elementos sem os quais o desenvolvimento da política se encontra em perfeita dissonância com as aspirações de uma sociedade que realmente aspire a consecução de valores democráticos.

Em um contexto como este de proliferação de debates em prol das liberdades por parte de indivíduos ciosos de que ela lhes fôra restringida, teve início o processo de desenvolvimento da América em temas constitucionais. Isto se deu em contexto de profundo diálogo com as circunstâncias de um tempo cujos atores, em maior ou menor medida, apreciavam a aristocracia a qual pertenciam, não raro apoiando o vil instituto da escravidão e dele extraindo proveito em todas as suas dimensões.

Jefferson e Madison emergem neste contexto como pensadores do fenômeno político mas também como ativos políticos, cuja maior preocupação era de cunho humanista. Este marco teórico dentro do qual desenvolviam seus trabalhos os fez eleger como preocupação nuclear as liberdades e os direitos do homem, malgrado suas contradições internas. Esta preocupação teve lugar em um bastante conturbado período histórico, o que tornava mais próximos aos nossos autores, muito embora suas divergências não pudessem ser desprezadas. Contudo, os conceitos sobre a organização republicana do Estado que haviam herdado da Antigüidade bem como de seus estudos acerca do Renascimento italiano tornavam certos ideais que os habitavam categorias que lhes aproximava.

A aproximação de Jefferson e Madison por ser lida também através de Koch, autora que sublinha que "these two philosophical statesmen brought 
their generous and humanistic political theories to the test of action, and action, as ever, necessitated compromise" (KOCH, 1984, p. 12) ${ }^{1}$ algo que, no que tange à filosofia política, poder ser sintetizado da seguinte forma: "Jefferson and Madison were trying to safeguard the people's liberty and expected the state help the rights of citizens" (KOCH, 1984, p. 123). ${ }^{2}$ Ambos estiveram do mesmo lado quando contraposto à perspectiva conservadora do partido de Hamilton. Isto sim, enquanto Jefferson pode ser aproximado com maior facilidade aos radicais democratas do período, pensadores como Tom Paine.

Thomas Jefferson (1743-1826) ${ }^{3}$ emerge no debate político e constitucional dos primeiros momentos em diálogo com os demais Founding Fathers, que se opunham a algumas das visões de sociedade e perfis de Estado que até então haviam experimentado fácil triunfo. Jefferson é visto por alguns estudiosos que lhe atribuem grau de originalidade em sua construção teórico-política (ver SHELDON, 1993, p. 71), embora seja posição contestada por não poucos que enxergam como maior virtude jeffersoniana a sua grande capacidade de diálogo com diversas fontes teóricas e áreas de conhecimento bem como de sintetizá-las em um pensamento próprio.

No que concerne a esta suposta originalidade do autor, o assunto deve merecer, ao menos, certa matização quanto às enormes dívidas com intelectuais de diversas origens. ${ }^{4}$ Há quem afirme que acaso não tenha ele sido a figura-chave para entender todo o processo revolucionário, seguramente foi um daqueles três ou quatro líderes intelectuais que determinaram o início e desenvolvimento de todo o processo revolucionário

\footnotetext{
${ }^{1} \mathrm{O}$ trecho acima comporta a seguinte tradução: "Estes dois homens de Estado trouxe suas generosas e humanísticas teorias políticas para o teste da ação, e a ação sempre necessita compromisso".

2 O trecho acima comporta a seguinte tradução: "Jefferson e Madison tentaram salvaguardar as liberdades populares e esperaram que o Estado socorresse aos direitos dos cidadãos".

${ }^{3}$ A leitura de Jefferson e a mais acurada interpretação de seus escritos, extensa e prolificamente apresentada sob a forma de correspondência, normalmente vem acompanhada de uma paralela leitura crítica de sua biografia e, logo, de suas contradições, tal como ser um dos grandes proprietários à época e, ao mesmo tempo, teórico libertário. A propósito desta possível abordagem, obra composta de forma sucinta mas valiosa é a de Appleby e Schlesinger, (2003). Com o mesmo escopo, ver a bem mais recente obra de Onuf (2007). Sobre Jefferson há, contudo, frondosa bibliografia, sobremaneira no que concerne à sua biografia.

${ }^{4}$ É fato que a formação e desenvolvimento do pensamento filosófico e teórico-político de Jefferson possui uma amplíssima gama de influências que, não obstante a vasta bibliografia produzida ao seu redor. Não é razoável supor que se encontre bem ponderado o assunto do peso de todas as suas fontes.
} 
bem como do seu desfecho a uma situação de maior normalidade institucional (cf. PATTERSON, 1967, p. 27).

Parece apropriado começar estas linhas por fazer referência a este tema que, em princípio, poderia parecer meramente secundário ou residual, devido ao fato de que, na seqüência deste artigo, algumas ideias que emergirão no trabalho parecerão bastante comezinhas e comuns a outros tantos filósofos políticos, tanto do período clássico como ainda contemporâneos de Jefferson.

No que concerne à sua compreensão e, não raro, oposição à aristocracia - ainda quando fosse um membro proeminente dela -, Jefferson nutre posição contraditória. Aristocrata e escravocrata, por outro lado, se apresentou como histórico defensor dos direitos humanos e muitas vezes denunciando, com este propósito, tanto a condição do negro como da mulher. Contraditória também foi sua posição quanto a busca pela difusão da educação e para que o Estado cumprisse seus fins mas, ao mesmo tempo, se desocupasse de que esta era uma arma eficiente para atacar as instituições aristocráticas da sociedade norte-americana que, por sua vez, corroíam as possibilidades de desenvolvimento da nascente república.

Em verdade, a Constituição norte-americana não alterou visceralmente o panorama filosófico-político vigente mas, antes, veio procurar reforçar as perspectivas libertárias dos colonizadores. A Carta vinha no sentido de aumentar a proteção daquelas liberdades que os levaram à imigrar da Inglaterra e, por fim, lutar pela independência até a afirmação de claros e fundacionais princípios postos na Declaração da Independência ${ }^{5}$ por Thomas Jefferson. Tal empenho teórico teria seus desdobramentos mais profundos à raiz da publicação do Federalista, que começara em outubro de 1787 (portanto, logo após o término da Convenção Constitucional) veio a ser concluída em maio de $1788,{ }^{6}$ data que contextualiza a partir de quando o documento teria maior publicidade e permitiria uma leitura mais ampla de seu conjunto.

\footnotetext{
${ }^{5}$ A quem queira introduzir-se na leitura sobre a Declaração da Independência é aconselhável a leitura da Summary View of the Rights of British America, datada do ano de 1774, na qual Jefferson adiantava a defesa do direito dos estados à independência quanto à elaboração de sua legislação. Interessa ponderar o papel deste documento, uma vez que apenas dois anos após observa-se a realização do Congresso Continental na Filadélfia que resulta na declaração de independência das então colônias norte-americanas relativamente à pátria-mãe.

${ }^{6}$ Coincidiu com este período preparatório da publicação conjunta do Federalista que Jefferson e Madison intensificaram a troca de cartas (cf. Koch, 1964, p. 49).
} 
Estes são alguns dos tópicos que este artigo procurará trazer à tona sem vislumbrar projetar demasiadas luzes mas, antes, focar alguns aspectos que nos possam resultar estimulantes para suscitar novos debates e combater a anemia cívica que, em certos momentos, parecem fazer padecer o espírito político pátrio. Nestes termos o ideal de autogoverno, e liberdade, prezados e pregados por Jefferson e, de longe, ideais republicanos perenes, parecem dificilmente alcançáveis.

\section{Republicanismo e democracia: 0 embate entre conservadores e radicais. 0 processo de afirmação do politico}

Jefferson fundamentalmente defende a estruturação e implementação de um necessariamente novo conceito de republicanismo na América, ${ }^{7}$ e os valores que nela deveriam vigorar encontravam características diferentes daquilo que até então se vira. Contudo, se a rota do mundo empírico se encontrava todavia aberto aos primeiros experimentos, o viés teórico, ao menos em alguns de seus aspectos, encontrava-se potencialmente presente no mundo anglo-saxônico bem como, não de forma completamente diversa, em alguns dos pensadores centrais da Revolução Francesa.

A defesa da tese de que há em Jefferson alguma teoria radical da democracia deve partir de, ao menos, dois pressupostos. Um deles é de que temos de entender a filosofia política jeffersoniana em seu contexto, sem o que nada daquilo que possamos concluir nestas linhas a respeito de um democrata radical poderá ser sustentado. Um segundo pressuposto diz respeito à ruptura institucional proposta por Jefferson relativamente ao mundo político, a saber, o distanciamento de uma monarquia britânica que encontrava em Jorge III a figura representativa do poder centralizado e em nada atento às demandas dos súditos. $\mathrm{O}$ ataque certeiro de Jefferson à esta instituição política centralizadora o aproximaria de radicais da democracia além-mar, tanto britânicos, como Tom Paine (ver PAINE, 1990) como franceses, através de Rousseau (ver ROUSSEAU, 2007, 2005). Este é o ponto de partida que desejamos explorar aqui.

\footnotetext{
${ }^{7}$ Convém ressaltar que este caráter de novidade do republicanismo norte-americano era devido à inexistência de uma teoria política então aplicável à realidade norte-americana, com seu vasto território, suas peculiaridades socioculturais bem como aos valores políticos de então, direcionados à busca da salvaguarda das liberdades, o que em muito distanciava o experimento norte-americano, por exemplo, do conceito de república presente na Antigüidade Grega.
} 
Jefferson pode manter-se próximo de Lafayette, nobre marquês que se ocupou em grande parte da redação da Declaração dos Direitos do Homem francesa, mas que, ao fim e ao cabo, teve de ceder espaço para que a Assembléia viesse a compartilhar da tarefa, e também redigir grande parte do texto, muito embora não tenha resultado, finalmente, capaz de organizar o trabalho a ponto de finalizá-lo. Após seis dias de debates os deputados terminaram por aprovar dezesseis de um total de vinte a quatro artigos (cf. HUNT, 2009, p. 14). Ali era perceptível implicitamente a ruptura que Jefferson realizara de modo explícito, a saber, que enquanto os franceses apenas não se referiam ao monarca, da parte de Jefferson havia positiva referência ao novo soberano, o povo. O que estava em jogo naqueles novos tempos era que, implícita ou explicitamente, haveria de ser considerada a nova era de substituição do soberano que, em qualquer caso, passava da figura do monarca à do povo. Este movimento representa o momento da ruptura que traria profundas conseqüências para todos os processos constitucionais que teriam curso não apenas naquele momento histórico como em toda a posteridade. ${ }^{8}$

Uma das referências teóricas para a compreensão do embate de base travado no processo de formação da cultura política norte-americana contra o pensamento conservador (e anti-revolucionário) era representado por Tom Paine. Apontado como um dos "radicais"," o autor busca na América um campo que se revelaria bastante fértil para ideias e ideais reformistas ou, até mesmo, revolucionários, os quais a Coroa Britânica, por óbvios motivos, não se mostrava proclive a defender nem mesmo aceitar a propagação em seu território. A defesa de que o poder político residisse no povo e não no poder supremo monárquico, ou seja, de que dependesse de consulta popular a tomada de decisões que a ele afetara, quer direta ou indiretamente a um poder político constituído por representantes eleitos e que aos seus constituintes respondera. A perspectiva monárquica já não mais se revelava

\footnotetext{
8 Todavia cabe acrescer a este respeito que se trata não apenas de referências formais como, posteriormente, a ideia de que o povo seja o soberano político haveria de ser apropriada pela hermenêutica jurídica para fins de aplicação das normas, inclusive constitucionais, em que pese este tenha sido um processo algo mais lento.

${ }^{9}$ Este é um conceito que deve ser entendido necessariamente dentro de seu contexto histórico, uma vez que aquilo que constituía o cerne do radicalismo à época hoje é entendido como um conteúdo mínimo das democracias de desenvolvimento médio. À época enquadrava-se entre os radicais todos os proponentes de direitos de voto a todos os indivíduos, sem qualquer relação às suas propriedades. Esta última era a visão dos conservadores do período.
} 
como algo razoável para período histórico que apresentara alta e derradeira fatura.

Estas concepções aproximaram Jefferson, um cético quanto ao poder que, ademais, nutria especialmente profundo desapreço pelas monarquias, o que era explicável tendo em vista as experiências históricas que Jefferson reputava altamente negativas quanto à proteção das liberdades. Entre despóticos e absolutistas, poucos eram os monarcas a constituir exceções, algo que não justificaria os riscos a correr. O poder corrompe, diria adiante Lord Acton, mas o poder absoluto corrompe absolutamente, máxima com a qual, perfeitamente poderíamos imaginar que Jefferson se mostraria de pleno acordo. Como remédio à concentração de poderes a teoria política de Paine e o republicanismo democrático de Jefferson apontavam para a consulta ao poder político soberano, o corpo político popular. A idéia inicial era de que tal consulta desanuviaria o processo de possíveis equívocos, momento em que a teoria rousseauniana da volontè general naturalmente emergiria como uma tese cuja projeção, embora não reflita direta e decisivamente sobre Jefferson, ${ }^{10}$ mostra-se em consonância com a defesa dos princípios a este respeito no duo Jefferson-Paine.

O diálogo que propomos aqui deve ser entendido como o de conservadores de uma estirpe diversa mas que, indubitavelmente, ativamente militaram contra o que na América foi entendido, primeiramente, como radicalismo democrático. Momento seguinte, nossa sugestão é de que estes últimos, como desde seu viés radical, empregam esforços pela defesa da causa das liberdades, mormente reputada como preocupação contra seus ataques por parte do governo.

Dentre aqueles cuja teoria pode ser aproximada ao conservadorismo, como Hamilton, e certamente Burke (ver BURKE, 1989), observa-se a ausência de esforços em disfarçar a preferência por um determinado tipo de governo que em nada se aproximava de visão humanista. Paralelamente, mostrava-se distante da garantia de direitos do homem que a Revolução Francesa erigira, e com os quais convergira a Revolução Norte-Americana (ver

$10 \mathrm{O}$ que proponho aqui não é que o pensamento jeffersoniano não possa ter sido influenciado por Rousseau. Ao contrário, é sabido o quão influente foi o pensamento revolucionário francês na densificação teórica não apenas do pensamento jeffersoniano como, de maneira ampla, na formação do político na América. O fato é que não temos evidências concretas desta recepção direta de Jefferson no que concerne à volontè general de Rousseau. Contudo, sua vivência e contínua interlocução com o pensamento francês do período revolucionário tornam mais do que provável que the tenha chegado, direta ou indiretamente, tal tipo de reflexão que teria incorporado ao seu corpo filosófico. 
DUNN, 2000). A rigor, não havia razões para tanto, pois suas predileções por regimes centralizadores, especialmente em Hamilton, remetiam a uma clara preferência pela monarquia e, em Burke, por um regime forte, mas não necessariamente monárquico, muito embora dele não excludente, afinal, no caso de Burke se tratava de alguém cujo texto-base, Reflexões sobre a Revolução em França, viria a ser reconhecido como literatura fundadora do moderno conservadorismo.

Hamilton e Burke compartilhavam o apreço pela tradição como excelente guia das virtudes cívicas, mas, à diferença do anglo-irlandês, Hamilton sentira, talvez por razões econômicas, mais do que por motivos morais ou políticos, forte inclinação a filiar-se entre aqueles que combatiam a escravidão e outras formas de produção distanciadas das emergentes estruturas urbanas e industriais de produção. Quanto ao primeiro caso, era aliado de Jefferson e, quanto ao segundo, decididamente, não poderia compartilhar do ideal de vida campesino do virginiano e suas necessárias implicações.

Enquanto Jefferson utilizava uma chave filosófica ligada ao Iluminismo para defender suas posições alicerçando-se nos direitos naturais dos homens, Hamilton e outros conservadores de superior estirpe como De Maistre, se sentiriam à vontade para defender aquilo que Burke, em seu momento, reputara como entes abstratos inexistentes, a saber, "o homem”. A rigor, De Maistre negava a existência do homem in abstrato em favor, tão somente, da existência de franceses, alemães, italianos, etc. (cf. DE MAISTRE, 1990, p. 66). Ao negar o universal, não resistiam as chances de admitir a necessidade de que os homens, por igual e em todo lugar, desfrutassem dos mesmos direitos.

\section{0 republicanismo como valor, a democracia como inspiração}

A democracia viria a ser tomada, em paralelo com o republicanismo, um valor-guia para a vida política norte-americana do período fundacional, não raro em algo enfrentados teoricamente.

Naquele contexto democrático era apresentado o debate sobre a boa sociedade e os valores que deveriam conduzi-la. Contudo, igualmente surgia a pergunta sobre o que se apresentaria a estes democratas como constituinte do bom governo e, em suma, quais seriam suas bases de sua legitimidade. Uma provisória resposta de Jefferson a esta questão dá conta de que 
(...) civil government being the sole object of forming societies, its administration must be conducted by common consent. Every species of government has its specific principles. Ours perhaps are more peculiar than those of any other in the universe. It is a composition of the freest principles of the english Constitution (...). (JEFFERSON, 1994, p. 211). ${ }^{11}$

Neste texto observamos certos traços que indicam que a democracia jeffersoniana pode encontrar aproximação a partir da ideia de consenso social em torno a valores e princípios. Jefferson destaca que a estrutura teórico-política norte-americana era devedora de valores libertários da cultura política e jurídica inglesa que entendiam não estar sendo devidamente cumpridos pelo poder político monárquico da época. A ideia revolucionária orientada pela democracia em Jefferson parece sugerir sobre a refundação da prático-teórica de valores ao invés de substituir os que já se encontravam consagrados na pátria-mãe.

Acerca desta refundação prática de valores Jefferson termina de fundamentar seu ponto de vista ao recorrer ao argumento de que o direito natural haveria de ser compreendido como forma de exercício prático da razão ou, em suma, que o poder político haveria de encontrar nesta fonte jusnaturalista, mas também jusracionalista, a sua fronteira e também limitação. Através da afirmação destes princípios em matéria teórico-jurídica Jefferson acreditava tornar-se factível uma mais eficaz defesa contra as monarquias absolutas (cf. JEFFERSON, 1994, p. 211).

Não obstante esta formulação inicial, o conceito de democracia à época opunha aqueles que a entendiam em sua forma clássica e aqueles que não a vislumbravam como possível apenas em territórios de diminuta extensão. Nestes últimos, entendiam alguns mais céticos, era onde ela a democracia era praticada de forma direta por cada um dos cidadãos. Esta era crítica diretamente endereçada às possibilidades da América, que não cumpria o requisito clássico da dimensão geográfica diminuta. Jefferson tentava contrapor o argumento ao dizer que “(...) that a government by

\footnotetext{
11 O trecho acima comporta a seguinte tradução: "o governo civil é o único objeto das sociedades, sua administração deve ser conduzida pelo consenso comum. Todos os tipos de governo tem os seus princípios específicos. Os nossos talvez sejam mais peculiares que todos os outros no universo. Esta é uma composição sobre os princípios libertários da Constituição inglesa".
} 
representation is capable of extension over a greater surface of country than one of any other form" (JEFFERSON, 1984, p. 1387). ${ }^{12}$ A virtude republicano-democrática não parecia realizável nesta esfera macro, e as lembranças clássicas eram o que estavam ainda presentes nos críticos dos Pais Fundadores. ${ }^{13}$

Podemos sinteticamente dividir em duas fases a filosofia política que repercutiu mais poderosamente tanto sobre a formação do discurso republicano na América quanto sobre a concepção e interpretação dos valores constitucionais. Naquele período haviam, ao menos, duas concepções sobre o republicanismo. Em uma delas, madisoniana, o conceito implicava um tipo de governo em que o poder é delegado para governar a um pequeno grupo enquanto que na democracia trata-se, à semelhança da Grécia clássica, do exercício direto do poder (cf. MADISON, 1993, X, p. 39). O pacto ou acordo proveria de limites a União para que exercesse o poder delegado. Em outro trecho Madison reafirmaria que em uma democracia cabe ao povo reunir-se para exercer a função de governo pessoalmente, enquanto em uma república se dá o processo político através de representantes (cf. MADISON, 1993, XIV, p. 53), em flagrante identificação do conceito de República com representação e democracia com intervenção direta nos assuntos públicos. Será dessa união de indivíduos em debate político que emergirá a opinião pública à qual Madison credita ser "the only real sovereign in a free government”. (apud KOCH, 1984, p. 128). ${ }^{14}$

Naquele período histórico este debate esteve longe de encontrar unanimidade. A este respeito há narrativas, por exemplo, de ele ter representado um verdadeiro entrave durante a realização da Convenção de $1787^{15}$ (cf. PATTERSON, 1967, p. 32) da qual, por certo, Jefferson não foi um membro, embora, isto sim, um bastante ativo interlocutor.

\footnotetext{
12 O trecho acima comporta a seguinte tradução: "(...) que o governo representativo é capaz de ser aplicado a países de grandes superfícies mais do que quaisquer outras formas de governo".

${ }^{13} \mathrm{~A}$ concepção de Madison, por exemplo, envolvia a oposição entre democracia e república.

${ }^{14} \mathrm{O}$ trecho acima comporta a seguinte tradução: "o único real soberano é o governo livre".

15 Para que observemos a elevação dos debates sobre o tema, diga-se que ele se encontrava sob exame desde, pelo menos, 0 ano de 1777. Nesta oportunidade Jefferson interferia no debate sugerindo a incorporação do sistema representativo, o que nos permite compreender que, não obstante sua adesão incondicional ao princípio da importância do governo local. Tratava-se era de que nele já encontrávamos 0 entendimento de que a viabilidade da União era indispensável a adoção da representação em escala federal. Contudo, a dualidade nacionalismo para assuntos externos e federalismo para dar sequência à política interna era uma divisa inegociável para o virginiano. (cf. Jefferson, 1786).
} 
Para Jefferson, o povo era o legitimador do exercício do mister político, e nada ou ninguém além dele, à sombra do critério validador do direito oferecido previamente por Blackstone, segundo quem não seria considerado direito o conteúdo que não estivesse em consonância com os preceitos do direito natural. ${ }^{16}$ Em Jefferson não seria legítimo o poder político, e nem jurídico o seu conteúdo, mas tão somente um abuso legal todo aquele conteúdo proveniente de uma outra fonte que não gozasse de apoio político na população.

A hipótese do exercício direto do poder, soa óbvio, apenas seria realizável naquelas circunstâncias presentes em pequenas sociedades. Por outro lado, para Jefferson, no fundo, trata de que um sistema republicano não dispensava o conceito de democracia presente em Madison, tudo isto porque, para o virginiano, a organização em wards implicava em âmbito federal um grau de representação que tornasse viável o Estado.

Madison chama a atenção para o fato de que as repúblicas podem compreender um maior número de cidadãos em uma maior extensão territorial (cf. MADISON, 1993, X, p. 39). Esta vantagem é logo matizada por ele dizendo que o governo nestas condições vê-se enfrentado com uma menor dificuldade quando administrativamente encontra-se subdividido. Desta forma, Madison dá guarida a ideia de Jefferson de divisão do Estado em wards (cf. JEFFERSON, 1816a) ${ }^{17}$ ou distritos de módicas dimensões que, como nos soa, remete ao ideal grego da polis. Jefferson reputada às wards como certo tipo de elementary republic (cf. JEFFERSON, 1816e, p. 1380). ${ }^{18}$

Há quem entenda que esta concepção de pequenos distritos nos quais o poder é exercido mais de perto (ward) é onde realmente se encontra a madura ou bem acabada teoria política de Jefferson (cf. SHELDON, 1993, p. 72). Estes pequenos distritos são o locus em que os indivíduos, dadas as suas dimensões geográficas, poderiam intervir diretamente nas deliberações da vida pública, ${ }^{19}$ mérito que asseguraria uma melhor organização da coisa pública.

\footnotetext{
16 Jefferson nunca ofereceu um mais bem acabado conceito de direito natural mas, antes, apenas afirmou tratar-se de uma lei da natureza que nos é dada por Deus, à qual é acessível através da faculdade da razão humana. A este respeito ver Patterson, 1967, p. 51.

${ }^{17}$ Nesta missiva dirigida a Cabell, Jefferson trata quase que exclusivamente deste tema.

${ }^{18}$ O trecho acima comporta a seguinte tradução: "repúblicas elementares".

19 Neste sentido também é perceptível uma aproximação da filosofia jeffersoniana aos preceitos do classicismo grego.
} 
Neste ponto Jefferson adaptou a concepção grega da polis para uma pujante e geograficamente hiperdimensionada realidade norte-americana, ou seja, às circunstâncias de um país continental. Sua ideia de divisão dos Estados em wards provém desta percepção de que a democracia direta originária da filosofia e da experiência grega - também repetidas e observadas em certa escala na Nova Inglaterra (lá denominadas de "townships") ${ }^{20}$ - não poderia ter qualquer chance não fosse nesta forma de organização com predominância do poder local e da participação dos cidadãos. ${ }^{21}$

Nestes termos, o entendimento era de que a participação dos cidadãos poderia dar-se nos termos propostos em sua citada carta para John Taylor (ver JEFFERSON, 1816c). Ali Jefferson mostrava-se ciente das limitações que a vasta extensão territorial impunha, algo que o fazia aceitar o conceito de representação política. Contudo, fazia-o sob certas limitações, posto que não adormecera sua natural desconfiança em poderes centrais, e não raro todavia intensamente centralizantes. Esta era uma leitura imposta à luz da história e, mesmo, da experiência política então recente, como o caso de vários países europeus.

Ficavam assim postas as condições para a defesa do autogoverno (selfgovernment nas wards jeffersonianas) que serviam como escudo teórico protetor contra a inspiração burkeana de governos baseados na tradição e que bem fundamentavam toda uma visão dinástica da organização social, em contraposição ao emergente republicanismo na vida norte-americana do período.

\footnotetext{
${ }^{20}$ A este respeito, e de forma entusiasta, Jefferson expressava em carta a Kercheval que aquela forma de organização em pequenos distritos (wards) tinha sido "the wisest invention ever devised by the wit of man for the perfect exercise of self-government, and for its preservation", circunstância na qual era possível "making every citizen an acting member of the government". (Jefferson, 1816d, p. 1399).

${ }^{21}$ Desde logo, uma questão que sobrevém é o que diria Jefferson em uma realidade global de grandes metrópoles. Mesmo nos EUA, o que diria ele sobre a organização de cidades como Nova lorque ou São Paulo? Uma forma de aproximação ao tema desde Jefferson é a estimular a organização de pequenos distritos dentro destas grandes metrópoles de sorte a aproximar o poder daqueles a quem governa.
} 


\section{0 ceticismo político e as bases da cultura jurídica norte-americana}

Uma das inspirações básicas da cultura política e jurídica da América que influenciou de forma definitiva sua conformação constitucional foi a desconfiança das estruturas daqueles que porventura se encontrassem em posição de exercer cargos de poder ${ }^{22}$ bem como de todas e quaisquer formas de representação política. ${ }^{23}$

Esta literatura é, talvez, o grande legado de Jefferson à cultura democrática na América seja esta sua desconfiança em governos e fé na potencialidade dos homens livres (cf. PATTERSON, 1967, p. 50). Enfim, que mais lhes convinha resguardar poderes em demasia antes que atribuí-los. Neste sentido Jefferson afirma que

(...) we think experience has proved it safer, for the mass of individuals composing society, to reserve to themselves personally the exercise of all rightful powers to which they are competent, and to delegate those to which they are not competent to deputies named and removable for unfaithful

\footnotetext{
${ }^{22}$ Neste sentido acreditamos que seja possível melhor explorar a influência de Maquiavel sobre 0 pensamento revolucionário norte-americano. Uma especial fonte para tanto é a obra de referência de Pocock. A este respeito ver Pocock, (2003). Este livro de Pocock é uma obra de referência para o estudo da retomada da questão republicana a partir de Maquiavel e, em geral, dos referenciais do Renascimento italiano, com a apropriação de figuras como Guicciardini e Giannotti. Será após tomar estes como referenciais teóricos que Pocock empreenderá uma travessia do Atlântico rumo à formação do pensamento republicano na América, e ponderando sobre suas influências na formação do pensamento político, o que para nosso trabalho neste artigo resulta importante na medida em que se revela determinante para a estruturação da estrutura filosófico-política e jurídica (constitucional) da nova realidade.

${ }^{23}$ Esta ideia de que não é possível confiar completamente (ou talvez ainda bem menos do que isto) nos representantes políticos é uma ideia recorrente em Jefferson. Isto fez com que 0 autor apoiasse um sistema de educação pública para que, minimamente instruídos, pudessem os cidadãos intervir diretamente nos debates sobre a política e os assuntos públicos. Jefferson ratifica tal ideia em vários trechos, dentre os quais suas Notes on Virginia bem como, e mais detalhadamente, em sua Bill for the More General Diffusion of the Knowledge, (1778). Nesta obra Jefferson nos diz que "it is believed that the most effectual means of preventing this would be, to illuminate, as far as practicable, the minds of the people at large, and more especially to give them knowledge of those facts, which history exhibited, that, possessed thereby of the experience of other ages and countries, they may be enabled to know ambition under all its shapes, and prompt to exert their natural powers to defeat its purposes". (Jefferson, 1984, p. 365).
} 
conduct, by themselves immediately. (JEFFERSON, 1984, p. $1385) .^{24}$

Para que pudéssemos ampliar estas possibilidades, o virginiano teorizava que haveria uma forma de divisão de competências entre União, Estados e Municípios que redundariam em melhorias às liberdades. Este ceticismo viria futuramente a inspirar a concepção dos checks and balances presente em diversas constituições ocidentais que, não obstante tal empréstimo, apenas indiretamente se nutriam da profundamente arraigada desconfiança do papel do poder central tão presente na cultura política norte-americana. Contudo, antes mesmo que a concepção dos checks and balances pudesse se tornar uma realidade influente, ainda quando em distante horizonte, Jefferson estivera na linha de frente, conjuntamente com os radicais, em defesa de uma especial concepção democrático-republicana cujo viés opunha-se a esta teoria.

Fundamentalmente, a argumentação jeffersoniana residia em que assumia que um de seus valores políticos mais caros, a saber, a necessária primazia do político - expressamente do Poder Legislativo - sobre os demais poderes deveria permanecer intocável quando tivessem em vista um regime essencialmente democrático. ${ }^{25}$ Acatar a teoria dos freios e contrapesos equivaleria a colocar os poderes em um mesmo e inaceitável nível, ao menos segundo os princípios teóricos dos radicais. Colocar o Poder Legislativo e os demais nesta situação lhes contrariaria tanto seu ceticismo como a abordagem metodológica do poder que até então consagraram.

\footnotetext{
${ }^{24} \mathrm{O}$ trecho acima comporta a seguinte tradução: "Nós pensamos que a experiência demonstrou-o mais seguramente, para a massa de indivíduos que compõem a sociedade, reservando para eles próprios 0 exercício de todos os poderes legais para os quais eles são competentes e para delegar todos aqueles para os quais eles não são competentes, para representantes escolhidos, imediatamente removíveis por condutas desleais pelos outorgantes do poder".

25 Não é deste tema que nos ocuparemos neste momento mas, isto sim, aqui reside um dos interessantes tópicos para exame quanto aos argumentos para a determinação da escolha do poder a quem atribuir competência para realizar 0 controle de constitucionalidade. Ao atribuí-lo ao Poder Judiciário resta 0 argumento contrário de que não foram sequer eleitos, restando manifesto, portanto, um déficit democrático. Por outro lado, ao atribuir ao poder executivo, restam em aberto por responder todas as objeções que o século XX propôs em termos práticos, principalmente nos anos 30 na Alemanha. Por fim, acaso seja este poder atribuído ao Legislativo, poderá ser pensado que o controle recairia em boas mãos mas, paralelamente, sofreria a objeção de que careceria de impactos históricos de maiorias interessadas em, por exemplo, desconstituir direitos de minorias constitucionalmente tutelados. Conforme comentado ao início, este não é o nosso objeto neste breve artigo, mas vale a pena assinalar a importância do tema para ulterior trabalho que propicia uma aproximação desde o direito constitucional à filosofia política.
} 
Nestes termos a discussão, durante longo período que podemos dizer haver sido concluído com a Constituição de 1786, a teoria dos checks and balances $^{26}$ foi defendida pela tradição conservadora que nisto percebia uma forma de proteção efetiva contra os suspeitos avanços dos radicais através da soberania do Poder Legislativo. Neste sentido, e tomando como ponto de partida este ceticismo ético que aplicaria à política com extensa repercussão, Jefferson sugeria, por exemplo, que

(...) national government be entrusted with the defence of the nation (...) State governments with the civil rights, laws, police; and administration of what concerns the State generally; the counties with the local concerns of the counties. (JEFFERSON, 1816d, p. 1380). ${ }^{27}$

Muito embora várias vezes em campos opostos, nesta particular ponderação sobre o papel da república como protetora de direitos, Hamilton concordava com Jefferson, uma vez que nela via a função de, além de proteger contra a opressão de seus governantes, também assegurar a proteção das injustiças de uma parte da sociedade contra as injustiças de outra parte (cf. HAMILTON et all., 1993, LI, p. 222). Esta é uma abordagem que se mostraria promissora para tempos vindouros, enquanto Jefferson, naquele momento, mostrava-se mais preocupado em aplainar o espaço político para o triunfo da vontade das maiorias, de cujas decisões deveria depender os destinos do processo legislativo (cf. JEFFERSON, 1984, p. 917).

A longo prazo a visão industrial-financista de Hamilton se mostraria mais promissora, devidamente ponderando que o seu triunfo, como sói ocorrer, não teve lugar de forma absoluta, senão parcial e relativa aos demais valores concorrentes. Parece certo dizer que Hamilton estivesse preocupado com as minorias, mas entendendo a estas como os pequenos grupos aristocráticos que exerciam o domínio político e econômico. O conceito se

${ }^{26}$ Teoria dos freios e contrapesos, utilizada no âmbito da tradição constitucionalista norte-americana cuja inspiração foi a equivocada leitura de Montesquieu das estruturas de poder da Inglaterra e que, logo após sua recepção nos EUA, iria projetar-se pelos países que, como o Brasil, mantiveram contato com a tradição constitucionalista norte-americana.

27 O trecho acima comporta a seguinte tradução: "(...) ao governo nacional pode ser confiada a defesa nacional da nação (...) aos governos estaduais, os direitos civis, as leis, a segurança e a administração do diga respeito em geral ao Estado; aos municípios, os assuntos locais dos municípios". 
projetaria a outros contextos históricos desde os quais uma leitura descomprometida com os seus propósitos se revelaria bastante promissora.

A preocupação de Hamilton não era, portanto, com o que contemporânea e majoritariamente nos referimos como minorias. Em seu caso, a preocupação era com a proteção das minorias que exercem o poder político e da supremacia econômica antes do que com mulheres ou negros, cuja situação no período era, de fato, péssima. Esta preocupação com as minorias, sendo invertida, faz com que este aspecto do pensamento de Hamilton desfrute de considerável atualidade, mormente quando atentamos às necessidades que apremiam os citados grupos de gênero e etnia nos dias que correm. Por outro lado, e em reforço a esta preocupação, muito embora desde uma ótica afim com as minorias cuja dependência as torna, desde certa ótica, presas a um sistema que deslegitima o exercício do poder contratual sob o qual todos vivem, nos dizia Jefferson que

Hence, with us, the people (by which is meant the mass of individuals composing the society) being competent to judge of the facts occurring in ordinary life, they have retained the functions of judges of facts (...) but being unqualified for the management of affairs requiring intelligence above the common level (...) they chose, for their management, representatives. (JEFFERSON, 1816b, p. 1385). ${ }^{28}$

Estando as pessoas aptas a tais julgamentos cotidianos, sendo elas dotadas por natureza da capacidade de raciocinar e de decidir sobre suas vidas, ${ }^{29}$ encontramos aqui um outro traço que reclama a influência iluminista em Jefferson. Já em outro célebre escrito, Notes on the State of Virginia, (1797b), Jefferson comenta o quanto um bom e livre governo depende de que não constituamos uma estrutura de poder em que este se encontre centralizado. Este era precisamente um de seus pontos de atrito com

\footnotetext{
${ }^{28}$ O trecho acima comporta a seguinte tradução: "Portanto, conosco o povo (e aqui isto significa a massa de indivíduos que compõem a sociedade) são competentes para julgar os fatos que ocorrem na vida corrente, eles mantém as funções de julgar os fatos (...) mas ser desqualificados para a administração dos assuntos que requeiram inteligência acima do nível ordinário (...) eles escolhem representantes para a sua administração".

29 Posteriormente Mill retornaria a esta temática para dar-lhe algum grau de sistematicidade e sofisticação argumentativa. Ver Mill, (1997).
} 
Hamilton, ${ }^{30}$ posto que não podia segui-lo em sua apologia do "extreme state's rights" (PATTERSON, 1967, p. 37). ${ }^{31}$ Ao contrário, diz Patterson, Jefferson era "neither of the extreme rights nor of the extreme left" $(I b),.{ }^{32}$ segundo a acepção que o extremismo pode ser compreendido na cultura norte-americana. Esta oposição com Jefferson, contudo, não era a única mas, apenas talvez, a mais intensa.

Nos limites do próprio Federalista encontramos oposição entre os madisonianos e os hamiltonianos, presentes suas duas visões de Estado. Uma, a de Madison, primava pelo entendimento de que o equilíbrio entre os poderes era fundamental, assim como de que se encontrasse dedicado à realização da justiça e da equidade bem como, e nisto compartilhava a visão jeffersoniana, de que a soberania era popular. Já a visão hamiltoniana, por outro lado, destacava a existência de um governo enérgico - contrário a Jefferson que se apresentara como alguém "not a friend to a very energetic government. It is always oppressive” (JEFFERSON, 1994, p. 917) 33 - fôra concebido com estrutura centralizada, ideias às quais Jefferson rechaçara tão

\footnotetext{
$30 \mathrm{O}$ embate entre Jefferson e Hamilton não teve apenas um ponto de disputa. No entanto, a questão sobre a centralização do poder, pode dizer-se, representou um dos mais fortes pontos de tensão entre ambos. Assim, por exemplo, enquanto para outro dos Founding Fathers, Madison, que mostrava entender que a União era o baluarte para a proteção contra os perigos internos e externos, para dinamizar o progresso em todos os níveis (cf. Madison, 1993, XIV, p. 52), Hamilton Ihe prestava apoio ao sustentar que 0 Estado deveria estar capacitado para enfrentar perigos iminentes. Assim, dizia no Federalista, no. XVI, que "el gobierno de la Unión, como el de cada Estado, ha de poder dirigirse de modo inmediato a las esperanzas y los temores de los indivíduos, así como traer en su apoyo aquellas pasiones que más influyen sobre el corazón humano. En resumen, para ejercer los poderes de que está investido, debe poseer todos los medios y tener el derecho de recurrir a todos los métodos que poseen y ponen en práctica los gobiernos de los diversos Estados" (Hamilton, 1993, XIV, p. 64-65). Hamilton sempre fôra um escritor a serviço da superação da estrutura confederada, a qual temia não resistir aos ataques de seus inimigos, quer internos quer externos. Era necessária uma estrutura política e jurídica capaz de dispor de poder para a consecução das finalidades que as pessoas esperavam de um governo (cf. Hamilton, et. all, 1993, XXIII, p. 92). Mas se uma diferença fundamental houvera de ser apontada entre Jefferson e Hamilton a este respeito ela encontra perfeita síntese no artigo XXIII do Federalista em que Hamilton sustenta que "es imprudente y peligroso negar al gobierno federal una autoridad sin límites sobre todos los objetos que sean encomendados a su administración" (op. cit., p. 95), muito embora matizasse, ainda que já causado o desconforto de sua afirmação inicial, de que seria importante que 0 povo estivesse atento à fiscalização das ações públicas. Desde logo, há inúmeras referências de Hamilton às virtudes do Estado perante a desconfiança de Jefferson quanto à centralização, como iremos observando no decorrer deste trabalho.

${ }^{31} \mathrm{O}$ trecho acima comporta a seguinte tradução: "direitos extremos do Estado".

32 O trecho acima comporta a seguinte tradução: "(...) nem da extrema direita nem da extrema esquerda".

${ }^{33} \mathrm{O}$ trecho acima comporta a seguinte tradução: "(...) não amigo de um governo muito enérgico. Isto é sempre opressivo".
} 
explícita e veementemente como pudera. Como se sabe, Hamilton foi defensor de um novo sistema econômico, enquanto Jefferson defendia um modo de vida predominantemente rural, aliás, próprio (e próximo) da grande maioria dos cidadãos norte-americanos do período.

Perante estas discrepâncias, a percepção de Jefferson era de que a distribuição de poder no Estado seria a melhor forma de que os constituintes pudessem encontrá-lo de maneira eficiente vir a controlá-lo. Daí a saudação a recepção de Montesquieu ${ }^{34}$ de que os três poderes encontrassem divididos e no exercício de três diferentes funções (cf. JEFFERSON, 1984, p. 245; cf. JEFFERSON, 1787a, p. 915). Esta divisão era o caminho para o bom governo, para um que conferisse segurança tanto aos cidadãos como às liberdades públicas. Assim, o caminho a ser trilhado para este bom governo supunha que fosse aplicada a ideia de que "(...) is not to trust it all one, but to divide it among the many, distributing to every one exactly the functions he is competent to". (JEFFERSON, 1816d, p. 1380). ${ }^{35}$

Estas são ideias retomadas e que ficam bastante claras no Federalista, bem expressas pelas múltiplas limitações dispostas ao poder em âmbito nacional como por outras formas que terminariam por erigir, embora à raiz da má interpretação de Montesquieu sobre os institutos ingleses, e a afirmação na América dos três poderes ${ }^{36}$ e do sistema de freios e contrapesos.

\section{Jefferson $e$ as condições do autogoverno}

Jefferson reitera os esforços contra qualquer tipo de despotismo, mesmo alguns que se apresentassem sob a forma eletiva. Isto sim, o aspirado governo prospectava e punha as reais condições para o triunfo da liberdade e do controle do exercício do poder pelos governados (cf. JEFFFERSON, 1984, p. 245).

\footnotetext{
${ }^{34} \mathrm{~A}$ obra política central de Montesquieu e que causou impacto na América foi mesmo $\mathrm{O}$ espírito das leis. Outras obras vieram a tornar-se de domínio entre alguns fundadores mas, sem dúvida, esta foi a obra-chave para o panorama da constituição política da época.

${ }^{35} \mathrm{O}$ trecho acima comporta a seguinte tradução: "(...) não é de se empregar irrestrita confiança a todos, mas dividir (o governo) entre muitos, atribuindo a cada um exatamente as funções para as quais sejam competentes".

${ }^{36}$ Aparte a admissão do esquema da tripartição pelos fundadores, Jefferson expressava em carta para John Taylor sua visão contrária à eleição dos membros de qualquer dos três poderes pela população, fora isto de forma direta ou indireta (cf. Jefferson, 1816c, p. 1393). De certa forma, foi uma visão que triunfou até os dias atuais em que a eleição para o Executivo nos EUA todavia não é realizada diretamente pela população embora, isto sim, indiretamente através da escolha de delegados em cada um dos Estados da Federação.
} 
A ideia de autogoverno se faria bastante presente em Jefferson. Em uma de suas cartas endereçadas a Cabell (ver JEFFERSON, 1816a) ${ }^{37}$ o virginiano sintetizou qual era a sua concepção do bom e seguro governo. Em observação de inconteste atualidade e utilidade, sugeria que o caminho a trilhar era o da desconfiança tanto quanto a governos quanto aos governantes. Para cumprir este mister de assegurar direitos e liberdades, melhor seria atribuir aos indivíduos poder autônomo ao povo, de sorte que, capazes, poderiam tanto contrabalancear quanto frear os excessos eventualmente cometidos por um ou outro dos poderes políticos.

Aspecto deste denodado ceticismo é que Jefferson nutria visão antropológica que se aproximava daquela apresentada por Madison ao se referir a que os homens precisavam de legisladores e leis na medida em que não apresentavam quaisquer dessas angelicais características ${ }^{38}$ que os tornasse dispensável, e nem sequer uma promessa crível de que pudessem, em algum momento, mesmo que futura e distantemente, demonstrar comportamento similar a angelicalidade. Em suas palavras, a ideia básica era de que

(...) si los hombres fuesen ángeles, el gobierno no sería necesario (...). Al organizar un gobierno que ha de ser administrado por hombres para los hombres, la gran dificultad estriba en esto: (...) hay que capacitar al gobierno para mandar sobre los gobernados; y luego obligarlo a que se regule a sí mismo. (HAMILTON, JAY e MADISON, 1993, LI, p. 220). ${ }^{39}$

É neste sentido que Madison alerta para uma concepção do político mas também do jurídico que cobra atualidade em culturas que privilegiam o formalismo e um essencialismo metafísico aristotélico em detrimento de uma

\footnotetext{
${ }_{37}$ Por outro lado, algo do que é dito até aqui pode até mesmo sugerir uma visão do Estado mínimo em Jefferson. Contudo, 0 autor não trata desta questão diretamente. Do que se trata é de que outras tantas competências que em uma Federação são atribuídas à União, Jefferson, dentre outros, as postulava como competências dos wards ou condados/municípios.

$38 \mathrm{O}$ certo é que mesmo Rousseau em sua visão antropológica benevolente fizera referência similar quanto ao governo. Sua proposição ideal é de que "um povo que governasse sempre bem (...) não precisaria ser governado" (Rousseau, 2007, livro III, cap. IV). Esta é a ideia que parece ter, igualmente com Hobbes, ter servido à Madison no famoso trecho citado no corpo de nosso texto.

39 O trecho acima comporta a seguinte tradução: "(...) se os homens fossem anjos, o governo não seria necessário (...). Ao organizar um governo que tem de ser administrado por homens para os homens, a grande dificuldade reside nisto: (...) tem de capacitar o governo para mandar sobre os governados e, logo, obrigá-lo a que se normatize a si próprio".
} 
perspectiva pragmática proclive ao utilitarismo ponderado. Como bem supôs Madison, os homens não apenas demonstraram sua inaptidão à angelicalidade como, em muitos casos, inábeis ou desinteressados, à promoção de instituições bem concebidas e sólidas o suficiente a ponto de servirem como mecanismo de defesa coletiva contra os avanços e torpezas particulares.

Há também neste alerta cético compartilhado por Jefferson, um certo viés da antropologia hobbesiana, muito embora, para o virginiano, melhor seria falar em um ceticismo ético mais do que um de ordem antropológico, por mais amplo. Contudo, à diferença da antropologia do filósofo de Malmesbury, para Jefferson, no reino da desventura moral, a única guardiã das liberdades individuais e públicas seriam os efeitos da disseminação da desconfiança relativamente aos exercentes do poder. Por outro lado, enquanto Hamilton e seus partidários advogavam pelo governo forte em vista dos perigos que vislumbrava, Jefferson se opunha dizendo não ser amigo dos hamiltonianos princípios que gravitavam em torno de um "very energetic government” (JEFFERSON, 1787a, p. 917) ${ }^{40}$ e, ao tempo, informava o motivo: "It is always opressive" $(I b.) .{ }^{41}$ Adams não foi menos incisivo a este respeito ao afirmar que

That men could never be governed by force, that neither virtue, prudence, wisdom nor anything else sufficed to restrain their passions (...). (KOCH, 1984, p. 139). ${ }^{42}$

Este argumento anuncia que para Jefferson o peso de seu ceticismo ético é inferior ao de sua profunda desconfiança não só quanto ao valor mas quanto à própria utilidade dos regimes de força para a estruturação de sistemas políticos livres. Historicamente os exemplos de regimes fortes ou, como dizia Hamilton, dos governos muito enérgicos, ${ }^{43}$ representavam tradições despóticas com as quais dissentia o virginiano. Ilustrativamente, Jefferson recorda o caso político-constitucional francês. ${ }^{44}$

\footnotetext{
40 O trecho acima comporta a seguinte tradução: "(...) governos muito enérgicos".

${ }^{41}$ Idem: "(...) Isto é sempre opressivo".

42 Idem: "Que os homens não podem ser governados pela força, que sequer a virtude, prudência, sabedoria nem qualquer outra coisa bastam para restringir suas paixões".

${ }^{43}$ Idem: "(...) governos muito enérgicos".

44 Jefferson menciona o seguinte trecho que vale transcrever: "(...) that the first National Conventn. of France had establd. a Constn., had excluded themselves from it's admm. for a certain time, a new set of
} 
Por seu turno, nos diz Koch, Madison reforçava a teoria de Jefferson sobre a concentração de poderes por parte dos governos pois, na medida em que isto tivesse lugar, poderíamos nutrir a desconfiança de que "governments that maintain excessive concentrated powers leave no man safe in his opinions, his person, his faculties, his possession. On the other hand, too much liberty might incur a similar insecutiry" (KOCH, 1984, p. 124). ${ }^{45}$ Esta é parte da argumentação do ceticismo que se encontra à base da cultura política norte-americana não apenas relativamente ao poder central mas a qualquer tipo de poder, em suma, contra excessos, mas que em necessidade de opção, o fará por eventuais danos decorrentes de excessos libertários.

Isto sim, é certo que em seu roteiro político Hamilton haveria de reconhecer o grande papel a ser exercido pelo povo, uma vez que o governo dele dependeria, em certa medida como eleitores e fiscalizadores de suas ações. Hamilton, bem como Adams, propunham um tipo de governo próximo ao modelo contra o qual a revolução havia lutado e que agora, em tempos de paz, eram ainda muitos os que se ocupavam em lançar mão de suas plumas para defendê-los. Para tanta concentração de força no Estado como aquela proposta por Hamilton, difícil é crer que o povo fora freio suficiente no sentido de contê-la (cf. HAMILTON, et. all., 1993, LI, p. 221). Em suma, sugerimos que o movimento legitimador de adquirir poderes era máscara apenas, posto que obviamente não disporia de suficiente força para deter um poder político constituído e em ação no sentido de destroçar as liberdades públicas.

Este é um diálogo que caracterizou uma das fases de estruturação institucional do período pós-revolucionário. A disputa essencial era entre dois grupos (republicanos e anti-republicanos) em que um, o primeiro, batiase pela afirmação do direito dos homens ao autogoverno enquanto o segundo debatia-se por manter o direito de exercer o poder político concentrado em poucas mãos. Enfim, tratava-se de embate entre um grupo que queria afirmar a liberdade política como direito popular e o outro que desejava um governo forte, na prática distanciado de tal influência.

successors had come, had demolished their Constitution, put to death all the leading characters concerned in making it, were now proceeding to make a new Constn. \& to exclude (...) that their succesors would it their turn demolish (...) and make a new Constn. and so on eternally till a force could be brought them into place to restrain them". (Koch, 1984, p. 139).

${ }^{45} \mathrm{O}$ trecho acima comporta a seguinte tradução: "(...) governos que mantém poderes excessivamente concentrados não legam proteção aos homens no que concerne às suas opiniões, suas pessoas, suas faculdades e suas posses. Por outro lado, muita liberdade pode incorrer em semelhante insegurança". 
Jefferson deu mostras de que sua concepção de liberdade não apenas derivava de uma percepção de problemas políticos e de uma boa recepção de Locke como também partia de uma concepção metodológica, tal como aponta Sheldon (cf. SHELDON, 1993, p. 143). Cético quanto ao centralismo, Jefferson visava que o poder fôra exercido o máximo possível pelos cidadãos e, no que não coubesse, indiretamente, através de representantes sobre os quais fosse possível exercer controle. Mesmo quanto à delegação de poderes, aconselhava não abrir mão de larga escala desses. A Bill of Rights viria a ser concebida como mais um documento legal que reafirma este caráter cético de Jefferson e que tinha em vista evitar invasões das liberdades por parte do mundo político e, em especial, do Estado, o qual era visto e entendido pelos federalistas, inspirados em Hobbes, como o único capaz de deter a natureza humana.

Em dado momento histórico a predominância era, portanto, do indivíduo perante o Estado, o qual deveria adaptar-se aos seus constituintes, antes que o inverso. Isto porque o Estado era a criatura, não o criador (já no século XX tornar-se-ia o todo-poderoso senhor de seus súditos), e que o pacto originário lhe atribuía funções, e não um quadro político em que restasse caracterizada a total alienação da tábua de direitos naturais dos homens. Estes não eram passíveis de transmissão, ainda menos de forma total e definitiva. Traço jusnaturalista, este remetia a uma afirmação positiva do homem como ser racional, um indivíduo que tinha como

(...) duty rational man to abolish all usurpation, to restore himself to the original status of his natural rights, and to establish a new order based on his consent. All legitimate institutions were the handiwork of man and were his servants. (PATTERSON, 1967, p. 46 ). ${ }^{46}$

Em outro trecho de carta do mesmo ano, desta feita endereçada a Dupont de Nemours, Jefferson retomaria o assunto para afirmar seu ponto de vista de que a primazia do indivíduo na determinação dos rumos de sua vida, e de suas escolhas. Isto, recorda a dois autores, Mill e Thoreau. Mill

\footnotetext{
${ }^{46} \mathrm{O}$ trecho acima comporta a seguinte tradução: "(...) o dever do homem racional de abolir toda a usurpação, de restaurar a si mesmo ao seu original status de seus direitos naturais bem como de estabelecer uma nova ordem baseada em seu consentimento. Todas as instituições legítimas foram obra humana e lhe foram subservientes".
} 
sustenta em Sobre la libertad (ver MILL, 1997), que as melhores escolhas para os indivíduos são mesmo aquelas que eles realizam enquanto seres humanos autônomos. Por sua vez, Thoreau em sua Desobediencia Civil y otros escritos, se mostraria amplamente contrário às intervenções do governo na vida privada confirmando parcialmente algumas das ideias jeffersonianas sobre a composição e lógica do funcionamento da política.

Malgrado as posições em contrário, Jefferson dizia não temer ao povo (cf. JEFFERSON, 1816d, p. 1400) mas, antes ao contrário, amá-lo. Este sentimento se projetava quando em sua condição de indivíduos autônomos e que, como tal, mereceriam o direito de emprestar os rumos que escolhessem às suas próprias vidas (cf. JEFFERSON, 1816b, p. 1386) antes do que vê-las de alguma forma conduzidas. ${ }^{47}$ Este era o sujeito que, à luz da teoria lockiana, era o titular do poder a quem, por conseguinte, deveriam os governantes prestar contas. Contudo, havia tradição firme a não compartilhar destas premissas jeffersonianas.

Muito embora possa parecer uma ideia trivial nos dias de hoje, à época grandes personagens como, por exemplo, Adams tinham o que dizer em sentido contrário: "that the people, when they have been unchecked, have been as unjust, tyrannical, brutal, barbarous, and cruel as any King or senate possessed of uncontrollable Power" (apud PATTERSON, 1967, p. 31). ${ }^{48}$ Esta é a visão federalista, de certa forma, conservadora, que se opunha à busca de afirmação. Seu argumento aparentemente tentava aproximar os defensores do republicanismo e da democracia dos argumentos que apoiaram os horrores praticados pelo jacobinismo francês. Era o debate entre anglófilos (federalistas) e francófilos (republicanos) mas também, e talvez principalmente, entre duas concepções de mundo cujo debate de fundo não era apenas cultural mas sim centrado nas diferentes concepções de natureza humana sustentadas por cada uma das tradições. Mas por qual motivo os republicanos poderiam ser aproximados aos franceses? A hipótese de Koch é de que

\footnotetext{
${ }^{47}$ Não resta dúvida de que neste particular Jefferson se apresenta de forma muito próxima aos ideais emancipadores fomentados pelo lluminismo.

${ }^{48} \mathrm{O}$ trecho acima comporta a seguinte tradução: "(...) que o povo, quando eles estiveram sem controle, foi tão injusto, tirânico, brutal, bárbaro e cruel como qualquer Rei ou senado em posse de poderes ilimitados".
} 
(...) they believed that people could govern themselves. Reason, discussion, and compromise were real and almost sacred activities - not reserved for the few, but attainable by the many (...) federalist party were convinced that the mass of men were fools. $\left(\mathrm{KOCH}, 1984\right.$, p. 137). ${ }^{49}$

Esta parecia ser uma aberta defesa da aristocracia. Em uma de suas milhares de cartas, Jefferson argumentava que tínhamos conhecimento histórico acerca da malevolência de governos caracterizados pela concentração de poderes. Neste ponto marcava distância de seu amigo Madison, para quem o real problema da tirania (e este era o real temor de Jefferson) encontrava-se na formação impulsiva das maiorias nos governos locais (cf. KOCH, 1964, p. 44). Antagonicamente à defesa de Adams quanto à propriedade, em ser mantida a visão de desconfiança também no exercício do poder pelo povo, Jefferson reforça que

We think experience has proved it safer, for the mass of individuals composing the society, to reserve to themselves personally the exercise of all rightful powers to which they are competent, and to delegate those to which they are not competent to deputies, named and removable for unfaithful conduct, by themselves immediately. (JEFFERSON, 1816b). ${ }^{50}$

O texto sugere certo grau de antevisão dos problemas com a ineficiência, quando não até mesmo ilegitimidade dos procedimentos da representação. A esta realidade se somariam preocupações com uma sociedade que seria, necessariamente, conflitiva, o que demandaria estruturas de mediação, como a do Poder Judiciário, que lhes arbitrassem os embates (cf. PATTERSON, 1967, p. 60). Assim, o tema viria à tona com força e reclamando decisão quando posta a questão em Marbury v. Madison, cujo

\footnotetext{
49 O trecho acima comporta a seguinte tradução: "(...) eles acreditam que as pessoas podem governar a si mesmas. Razão, debate e compromisso foram atividades concretas e quase sagradas - não reservadas para poucos, mas alcançadas por muitos (...) o partido federalista estava convencido que as massas eram tolas".

50 O trecho acima comporta a seguinte tradução: "Nós pensamos que a experiência demonstrou seguramente para a massa de indivíduos que compõem a sociedade, que devem reservar para eles próprios o exercício de todos os direitos legais para os quais eles são competentes, e delegar todos aqueles para os quais eles não são competentes não são competentes, para representantes escolhidos, imediatamente removíveis por condutas desleais pelos outorgantes do poder".
} 
eixo argumentativo era a competência, ou não, do Poder Judiciário para declarar a inconstitucionalidade de normas jurídicas provenientes e aperfeiçoadas e tornadas vigente pelo Poder Legislativo.

\section{Considerações finais}

Neste contexto de embates e disputas acirradas na formação política dos Estados Unidos da América, Jefferson mostra toda a diversidade dos indivíduos e também toda a sua própria peculiaridade relativamente aos demais. A sua opção é de que de tal diversidade deriva o conceito de diferença de opiniões, cujo impacto refletiria daí em frente em diversos campos, desde o estritamente filosófico ao jurídico, em especial no constitucional.

A pluralidade de opiniões entre os homens era, para Jefferson, uma realidade tão evidente quanto a de raças (cf. JEFFERSON, 1814, p. 13281329) e, nesta medida, inabordável do ponto de vista de leis humanas de cunho restritivo. Cabia, portanto, até mesmo lançando mão da competência de controle constitucional derivada de Marbury v. Madison, proteger estas liberdades e os direitos do homem não apenas da opressão do governo como, e não raramente, dos excessos praticados pelo Poder Legislativo.

Era evidente e pulsante a preocupação com as diferenças de opinião, a busca pela consagração da liberdade de expressão adviria como conseqüência lógica, ocorreu em Jefferson. Esta possibilidade de livre trânsito e manifestação das ideias era categoria necessária a operacionalidade para a manutenção de congruência discursiva no esquema republicano jeffersoniano. A conjugação de liberdades e o roteiro do republicanismo apenas poderiam ser protegidos no contexto político de então através de ações políticas cidadãs ${ }^{51}$ o que, como se deduz, estava intimamente ligado ao direito de livre expressão, algo que encontraria consagração histórica no desenvolvimento constitucional norte-americano. Com isto podemos provisoriamente concluir o quanto algumas categorias centrais da experiência política, filosófica e constitucional norte-americana dependeram de uma tutela efetiva que, ao longo da história, o Poder Judiciário e, em especial, a Suprema Corte Norte-Americana, iria mostrar-se apta a conceder.

\footnotetext{
${ }^{51}$ Sugerimos existir algum proveito na projeção em algum grau a extensão desta reflexão para os dias
} atuais. 
Embora não direta e detalhadamente, Jefferson sugeriu que o cerne do conceito de uma república em que se desse a opção pela democracia representativa. Ainda que Jefferson admitisse como preferencial e desejável a democracia direta, paralelamente, reconhecia a inviabilidade de praticá-la de forma direta e em vastos espaços territoriais. Um dos remédios possíveis sugeridos era que os representantes pudessem ser removidos imediatamente de seus cargos em caso de perpetração de abusos (cf. JEFFERSON, 1816b, p. 1387). Esta ideia presente em Jefferson estava, com certas matizações, também presente em Locke quando teorizava sobre o direito de rebelião, uma vez constatados abusos por parte dos governantes.

Em Jefferson o afastamento do poder tinha fundamento último de que os governantes lá estavam era para representar o povo adequadamente no exercício do poder que lhes fôra confiado. ${ }^{52}$ Sobre este tema há inúmeras referências em Jefferson. Em uma delas, em sua célebre e influente Declaração da Independência, o autor defende o princípio de que a base de todo governo é o consentimento dos governados e que, por conseguinte, daí não poderíamos extrair ação política governamental legítima quando a ofensa ao público seja a marca indelével.

Em outro momento, como lembramos, Madison afirmara que os homens necessitavam de governo, posto que, revivendo em parte a tradição hobbesiana, dizia que eles nada tinham de anjos. Jefferson não diria algo muito distinto ainda quando não fora um hobbesiano quando punha em perspectiva o futuro da humanidade, o qual dizia encontrar-se em dependência da educação, tema este que nos remete a um outro texto, muito embora mantenha com este o elo dos direitos do homem a inspiração ilustrada.

\section{REFERÊNCIAS BIBLIOGRÁFICAS:}

ALFIN, D. C. Burke: circunstancia política y pensamiento. Madrid: Tecnos, 2006.

\footnotetext{
52 Neste aspecto haveríamos de recordar certo Ministro de nosso Supremo Tribunal Federal que de forma bastante lúcida ao ver-se enfrentado a julgamento de ação relativa à prática de nepotismo no Poder Judiciário reiterava que dos mandatos há quem tome posse no cargo, mas, outros, tomam mesmo posse do cargo, o que evidencia flagrante conduta avessa a mínimos princípios republicanos.
} 
APPLEBY, J.; SCHLESINGER, A. M. Thomas Jefferson. New York: Times Books, 2003.

BERLIN, I.; LEBRUN, R.. Maistre: Considerations on France. Cambridge / USA: Cambridge, 1994.

BUENO, R. "As origens do constitucionalismo: em torno ao debate Jefferson-Madison”. In: Revista da Faculdade de Direito de Uberlândia. V. 37, jan.-dez., 2009, p. 339-372.

.; POZZOLI, L. "Humanismo, justiça e democracia". PUC-Viva no.

18. Disponível em: http://www.apropucsp.org.br/revista/r18_r16.htm. Acesso em 10 de abril de 2009.

BURKE, E. Reflexiones sobre la Revolución en Francia. Madrid: RIALP, 1989.

BUTLER, M. Burke, Paine, Godwin and the Revolution Controversy. Cambridge: Cambridge University Press, 1984.

CONSTITUTION OF THE UNITES STATES OF AMERICA, The. St. Paul, Minn.: West Publishing Co., 1995.

DE BONALD, L. A. Teoría del Poder Político y Religioso. Madrid: Tecnos, 1998.

DE MAISTRE, J. Consideraciones sobre Francia. Madrid: Tecnos, 1990.

DUNN, S. Sister Revolutions: French Lightning, American Light. London, UK: Faber \& Faber, 2000.

GARGARELlA, R. The Scepter of Reason. Dordrecht, Boston, London: Kluwer Academic Publishers, 2000.

HAMILTON, A.; JAY, J. e MADISON, J. El federalista. México: Fondo de Cultura Económica, 1994.

HOLMES, O. W. Schenck v. United States. Nos. 437, 438. Supreme Court of the United States. 249 U.S. 47. January 9, 10, 1919. March 3, 1919. In: http://www.bc.edu/bc_org/avp/cas/comm/free_speech/schenck.html.

Acessado em 13 de abril de 2009.

HUNT, L. A invenção dos direitos humanos. Uma história. São Paulo: Cia. das Letras, 2009. 
JEFFERSON, T. "Declaration of Independence". In: PETERSON, M. D. (Org.). Writings of Thomas Jefferson. New York: The Library of America, 1984.

- "Notes on the State of Virginia". In: PETERSON, M. D. (Org.). Writings of Thomas Jefferson. New York: The Library of America, 1984. p. 123-325.

. "Letter to Joseph Cabell. February 02, 1816a”. In: PETERSON, M. D. (Org.). Writings of Thomas Jefferson. New York: The Library of America, 1984. p. 1377-1381p.

. "Letter to P. S. Dupont de Nemours. Poplar Forest, April 24, 1816b”. In: PETERSON, M. D. (Org.). Writings of Thomas Jefferson. New York: The Library of America, 1984. p. 1384-1388p.

. "Letter to John Taylor. Monticello, May 28, 1816c". In: PETERSON, M. D. (Org.). Writings of Thomas Jefferson. New York: The Library of America, 1984. p. 1391-1395p.

. "Letter to Samuel Kercheval. Monticello, July 12, 1816d". In: PETERSON, M. D. (Org.). Writings of Thomas Jefferson. New York: The Library of America, 1984. p. 1395-1403.

. "Letter to Corrèa da Serra. Poplar Forest, April 26, 1816e". In: PETERSON, M. D. (Org.). Writings of Thomas Jefferson. New York: The Library of America, 1984. p. 1388-1391.

. "Letter to Isaac Tiffany. August 26, 1816f". In: PETERSON, M. D. (Org.). Writings of Thomas Jefferson. New York: The Library of America, 1984.

.Letter to John Manners. Monticello, February 22, 1814. In: PETERSON, M. D. (Org.). Writings of Thomas Jefferson. New York: The Library of America, 1984. p. 1329-1333.

"Letter to John Wayles Eppes. Monticello, June 24, 1813a". In: PETERSON, M. D. (Org.). Writings of Thomas Jefferson. New York: The Library of America, 1984. p. 1280-1286.

. "Letter to Isaac MacPherson. Monticello, August 13, 1813b". In: PETERSON, M. D. (Org.). Writings of Thomas Jefferson. New York: The Library of America, 1984. p. 1286-1294. 
"Letter to John Tyler. Monticello, May 26, 1810". In: PETERSON, M. D. (Org.). Writings of Thomas Jefferson. New York: The Library of America, 1984. p. 1225-1227.

"Letter to James Madison. Paris, September 06, 1789". In: PETERSON, M. D. (Org.). Writings of Thomas Jefferson. New York: The Library of America, 1984. p. 959-964.

. "Letter to St. John de Crèvecoeur. Paris, August 9, 1788". In: PETERSON, M. D. (Org.). Writings of Thomas Jefferson. New York: The Library of America, 1984. p. 928-929.

"Letter to Maria Cosway. Paris, April 24, 1788”. In: PETERSON, M. D. (Org.). Writings of Thomas Jefferson. New York: The Library of America, 1984. p. $921-922$.

. "Letter to Madison. Paris, December 20, 1787a". In: PETERSON, M. D. (Org.). Writings of Thomas Jefferson. New York: The Library of America, 1984. p. $914-918$.

. "Notes on the State of Virginia. 1787b". In: PETERSON, M. D. (Org.). Writings of Thomas Jefferson. New York: The Library of America, 1984. p. 123-325.

. "Letter to Madison. December 16, 1786". In: PETERSON, M. D. (Org.). Writings of Thomas Jefferson. New York: The Library of America, 1984.

. "Bill for the More General Diffusion of the Knowledge. 1779". In: PETERSON, M. D. (Org.). Writings of Thomas Jefferson. New York: The Library of America, 1984. p. 365-373.

"Letter to Edmund Pendleton. August 26, 1776". In: http://en.wikisource.org/wiki/Letter_to_Edmund_Pendleton__August_26,_1776. Acesso em 20 de junho de 2009.

KOCH, A. Jefferson \& Madison. The Great Collaboration. New York: A Galaxy Books / Oxford University Press, 1964. 294p.

KRAMNICK, I. (Org.). Edmund Burke. New York: Penguin Books, 1999. 688p. 
LEBRUN, R. Joseph de Maistre - An Intellectual Militant. Paris: McGillQueen's Université, 1988.

LOCKE, J. Segundo Tratado sobre el Gobierno Civil. Madrid: Alba, 1986.

MADISON, J. Carta para Monroe. Philadelphia, December 4, 1794.

. "Spirit of Governments. National Gazette, February 20, 1792a, VI". In: http://classicliberal.tripod.com/madison/spirit.html. Acesso em: 08 de junho de 2009.

"Property. National Gazette, March 29, 1792b, VI". In: http://www.vem.duke.edu/POI/madison.pdf. Acesso em: 10 de junho de 2009.

MAISTRE, J. de. Considerations sur La France Suivi de Essai sur le Principe Generateur des Constitutions Politiques. Paris: Complexe, 2006. . Consideraciones sobre Francia. Madrid: Tecnos, 1990.

MELO, M. P. C. "A Suprema Corte dos EUA e a judicialização da política”. In: VIANNA, L. W. (Org.). A democracia e os três poderes no Brasil. Belo Horizonte / Editora UFMG; Rio de Janeiro: IUPERJ / FAPERJ, 2002. P. 6389.

MILL, J. S. Sobre la libertad. Madrid: Alianza, 1997.

MONTESQUIEU. El espíritu de las leyes. Madrid: Tecnos, 2007.

ONUF, P. Mind of Thomas Jefferson. Virginia: Virginia University, 2007.

PAINE, T. El sentido común y otros escritos. Madrid: Tecnos, 1990.

PATTERSON, C. P. The Constitutional Principles of Thomas Jefferson. Gloucester, Mass.: Peter Smith, 1967. p. 26-68.

PETERSON, M. D. (Org.). Writings of Thomas Jefferson. New York: The Library of America, 1984.

POCOCK, J. G. A. The Machiavellian Moment. Florentine Political Thought and the Atlantic Republican Tradition. Princeton: Princeton University Press, 2003.

PLATÃO. A República. Lisboa: Fundação Calouste Gulbenkian, 1998.

ROUSSEAU, J.-J.. El contrato social. Madrid: Tecnos, 2007. 
. Discurso sobre el origen de la desigualdad de los hombres. Madrid:

Tecnos, 2005.

SHELDON, G. W. The Political Philosophy of Thomas Jefferson. Baltimore \& London: The Johns Hopkins University Press, 1993. 174p.

SUPREME COURT OF THE UNITED STATES OF AMERICA. Aiken v. Wisconsin, 195 U.S., 194, 205-206.

. Roe v. Wade. 1973.

. Brown v. Board Education of Topeka, 1954.

. Gitlow v. New York, 1925.

. Schenk v. United States, 1919.

. Marbury v. Madison, 1803.

THOUREAU, H. D. Desobediencia Civil y otros escritos. Madrid: Tecnos, 2005.

Recebido em: fevereiro de 2011 Aprovado em: maio de 2011

Email: rbueno_@hotmail.com 